\title{
Research Progress of Antecedents of Organizational Identification
}

\author{
Somchit Hongvichit ${ }^{1}$ \\ ${ }^{1}$ Glorious Sun School of Business and Management, Dong Hua University, Shanghai, China. \\ Correspondence: Somchit Hongvichit, Glorious Sun School of Business and Management, Dong Hua University, \\ Shanghai, China.
}

Received: September 29, 2015

Accepted: October 12, 2015

Available online: October 16, 2015

doi:10.11114/ijsss.v3i6.1148

URL: http://dx.doi.org/10.11114/ijsss.v3i6.1148

\begin{abstract}
Organizational identification is one of the main concepts studying the perception of oneness with or belongingness to the organization in the organizational behavior which has an important influence on organizational performance, employee attitude and behavior. According to the recent research on the antecedents of organizational identification, this paper focuses on the research of dynamic and visual angle in recent years both domestic and international, summarize the characteristics of the factors are antecedents of organizational identification influence, mechanism of different types of organizational identification and its effect. Study on the tendency of organizational identification antecedents, to enrich the research system of organizational identification.
\end{abstract}

Keywords: Organizational identification, Antecedent, Mechanism, Future direction

\section{Introduction}

Organizational identification generally refers to the individual's psychological dependence on the organization, and from the perspective of cognition, emotion and behavior to determine the sense of belonging and sense of belonging. The influence of organizational identification has become the focus of the study, mainly from the external organization, the organization and combination of three individual factors with internal and external environment, study on the dynamic changes of the life cycle of the organization. Study on the antecedents of organizational identification and presents from the general to the particular, from the whole to the individual, from effect factor selection to mechanism of influencing variables. Overall, the study presents the characteristics of diversification and the diversification of the analysis perspective. Base on the research progress of domestic and foreign researchers in recent years, this paper tries to sum up both characteristics and mechanism of the research aspects. To enrich the theoretical research of organizational identification and guide the practice of enterprises.

\section{Literature Review}

The classification of structural factors on organizational identity antecedents of domestic and foreign scholars are basically the same, the main factors included qualitative or quantitative analysis of the organization external factors, organization factors and individual factors. In Table 1, can be found in recent years, analysis on organizational identity antecedents showed the following characteristics:

\subsection{The research on the external factors of the organization has been basically finalized}

In recent years, there is not much in-depth study on the external factors, Ashforth (1992) proposed for the significance of external factors, Morgan (2004) proposed the organization reputation, family member influence, the public or the customer's appraisal all are the key factor which affects the organizational identification. The external factors of the organization can satisfy the continuity of the individual's self-concept, improve the individual's difference and self-esteem, and thus cause the employees to identify with the organization.

\subsection{Organizational culture atmosphere Supportive and human resource policy practice has caused more attention}

In recent years, researchers have begun to pay attention to the supportive organizational culture atmosphere, organization internal leadership behavior, human resources policy and the influence of organizational level factors such as practice...etc. In field of empirical research on the cultural atmosphere of multi type organizations, Lin Wen Quan et al. (2008) found that there is a significant positive impact on organizational identification of employees in the innovative culture and supportive culture which supports the role of culture is more powerful, bureaucratic culture has a 
weak positive effect on the emotional identity of employees, the negative influence of cognitive identity is not significant. Qin Zhi Hua et al. (2010) pointed out that the leadership to provide material and emotional need to the membership will lead to a high quality of exchange relationship between leadership and membership. Wang Bi Ying et al. (2011) suggested that the leadership in the organization has an important role in the organizational identification of the employees; the leadership of the organization's identity will pass down to the organization's identity. Martin R. Edwards (2009) pointed out that the open team meetings; work autonomy, process fairness and progress opportunity in the organization have different effects on the organizational identification of employees in different stages of development. Many domestic researchers have also studied the influence of human resource policies and practices on the organizational identification of employees and using multi layer linear model analysis technique (Wang Zhen et al. 2011). At the same time, some scholars pay attention to the influence of the specific human resources policy, and the positive effect of the organization's internal flow and the incentive compensation (Li Yan 2011).

Table1. The antecedents of organizational identification

\begin{tabular}{|c|c|c|}
\hline Factor classification & Factor & Research method \\
\hline \multirow{3}{*}{ External factors } & $\begin{array}{l}\text { The significance of external factors } \\
\text { (Ashforth\&Mael1992) }\end{array}$ & Quantitative study \\
\hline & Organizational prestige (Dutton1994) & Quantitative study \\
\hline & $\begin{array}{l}\text { Organizational reputation, family members, public or } \\
\text { customer evaluation (Morgan2004) }\end{array}$ & Qualitative analysis \\
\hline \multirow{10}{*}{ Organizational factors } & $\begin{array}{l}\text { Human resources environment: open team meetings, } \\
\text { work autonomy, process fairness, and opportunities for } \\
\text { advancement (Martin R. Edwards 2009) }\end{array}$ & Quantitative study \\
\hline & $\begin{array}{l}\text { Provide material, career development training, and } \\
\text { relationships (Morgan2004) }\end{array}$ & Qualitative analysis \\
\hline & Organization support （Martin R. Edwards2010) & Quantitative study \\
\hline & $\begin{array}{l}\text { Open organizational communication (Bartels et al. } \\
\text { 2010) }\end{array}$ & Quantitative study \\
\hline & $\begin{array}{l}\text { Psychological contract violation (Thomas J. Zagenczyk } \\
\text { et al. 2011) }\end{array}$ & Quantitative study \\
\hline & $\begin{array}{l}\text { Human resource management policy (Wang Zhen et al. } \\
\text { 2011) }\end{array}$ & Quantitative study \\
\hline & $\begin{array}{l}\text { Internal flow and incentive payin human resources } \\
\text { policy (Li Yan 2011) }\end{array}$ & Quantitative study \\
\hline & Organizational culture types (Ling Wen Quan 2008) & Quantitative study \\
\hline & $\begin{array}{l}\text { Leadership within the organization (Wang Bi Ying et al. } \\
\text { 2011) }\end{array}$ & Quantitative study \\
\hline & Corporate social responsibility (Lu Tao et al. 2009) & Quantitative study \\
\hline \multirow{7}{*}{ Individual factor } & $\begin{array}{l}\text { Five personality extraversion, neuroticism (Johnson } \\
\text { 2005) }\end{array}$ & Quantitative study \\
\hline & Tenure, age, job level（Martin R. Edwards 2009) & Quantitative study \\
\hline & Marginal decline of tenure (Bartel 2001) & Quantitative study \\
\hline & Individual self concept and motivation (Danielle & \\
\hline & Cooper, Sherry M. B. & Qualitative analysis \\
\hline & Thatcer 2010) & \\
\hline & Psychological empowerment (Chen Hao 2010) & Quantitative study \\
\hline
\end{tabular}

\subsection{Individual influence factors pay more attention to individual cognition and psychological factor}

In the study of demographic variables, Johnson (2005) pointed out that "extraversion of big five personality" in the positive influence of organizational identity, organizational identity and neuroticism negative influence. Martin R. Edwards (2009) survey found that employees age, tenure, position level will affect the organization's identity, lower organizational identification is belong to those younger employees; The longer term or service are more likely to identify with the organization; Management is more likely to identify with the organization. Subsequently, researchers began to pay attention to the influence of individual motivation, psychological empowerment and other cognitive and psychological variables on organizational identification. Danielle Cooper \& Sherry M. B. Thatcer (2010) studies show that the individual's self-concept and motivation affect the organization; work team groups level and colleagues; Subordinate and superior relational level of recognition. Chen Hao (2010) pointed out that the four dimensions of 
psychological empowerment have positive influence on the degree of individual organizational identification, and the influence degree of each dimension is different.

\section{Method}

Most researchers analyze the mechanism of the process to be different. Respectively, the symbolic process of information transmission, social exchange mechanism, operation process of enterprise development cycle, organizational consistency, identification process and comprehensive theory analysis of the mechanism of antecedent variables on organizational identification.

\subsection{The symbolic of information transmission process}

The symbolic of information transmission process explains how the information is transmitted in a one-way process. Organization through the practice of human resources to issue a signal to pay attention and respect for employees, corresponding to the identity of a member of their identity. These signals enhance the self-esteem of employees, so that the individual has a positive perception of the organization, and then want to define their own identity. Tyler, T.R \& S.L., Blader (2003) developed a group input model to explain how people put into and identify with the organization as a result of the organization's process of fair elements to convey important information about how to treat them, and pointed out that the organization of the process of fair and indirect through the organization's identity to affect the cooperation between employees. Subsequently, the model is applied to explain the organization's many human resource practices. Sun et al. (2007) pointed out that the organization through the high performance of human resource practices, to provide employees with the support of the system environment such as providing job security, wide range of skills training, internal promotion, results oriented assessment and a wide range of career paths. These series support the practice of the organization to establish long-term cooperative relationship with the employees, the interests of the organization and the employees, so it can motivate employees to achieve the recognition of the organization's goals. Fuller et al (2006) proposed that when an organization is fair and respectful to the employees, provide information to employees who have been valued, actively promote the production of employee self-esteem, improve the self-esteem of members is the key to identify the driving mechanism; the employees will put more investment in the organization.

\subsection{Social exchange mechanism}

The exchange between the organization and the employee is the core of the social exchange system, the organization provides a specific incentive for employees to lead to the formation of an exchange relationship especially when the organization provides emotional support to employees, to promote the integration of the identity of the organization and the role of the role as their own social identity. Eisenberger et al. (1986) pointed out that the key to the social exchange relationship in the work is to determine the degree of organizational support and the perception of employees, employees will put the part of organization membership identity into their own identity. Therefore, it will form a positive emotional connection with the organization. According to the principle of reciprocity, the sense of organization support to encourage employees to generate more responsibility on work, employees are encouraged to exchange with the psychological and emotional dependence of return, and return to the organization through organizational identification. Martin R. Edwards (2009) established the mechanism model of the effect of employee's perception of the human resource in the organization.

\subsection{Operation process of enterprise development cycle}

Research on the mechanism of the process of enterprise's development cycle in the process of organizational identification, researchers are based on the whole process from the creation of the enterprise, the difference between the different stages of the enterprise human resource practices in the different stages of enterprise development. Martin R. Edwards (2009) empirical test of the impact of a variety of HR policies and practices within the organization on the organizational identity of employees, these policies include open team meetings, work autonomy, process justice and promotion opportunities. The different stages of the establishment of the organization to affect the organizational identification are different. Taking Trust (the newly established organization of UK National Health Service) as the research object. 7 months after established, the survey show that the organization open team meeting is an important measure of organizational identification. Because open team meetings involve information related to new organizations, this is a newly established organization to communicate with employees, these communication information to promote the recognition of employees. But 20 months later, found that the job autonomy, the process of equity and improve opportunity giving more sense of identity and lead to organizational identification. And no matter which stage, if organizations take decisive action when employees are harassed, discrimination or bullying will promote the organizational identification.

\subsection{Organizational consistency}

Thomas J. Zagenczyk et al. (2011) based on the psychological contract research organization policy and practice to the 
organizational identification. When the organization failed to fulfill these commitments (organization is contrary to psychological contract) will lead to employees think that the organization does not pay attention to their contribution, makes employees feel that they are not valued employees. Finally, the degree of employee's organizational identification is reduced even a higher degree of non-organizational identification. In particular, when the psychological contract of the organization violates the social emotional and physical needs of employees, employees can reduce the degree of their identification. Lu Tao et al. (2009) empirical investigation found that the enterprises to fulfill the environmental responsibility, employee responsibility, community responsibility and customer responsibility have a significant positive impact on organizational identification. Higher organization social responsibility performance lead to higher degree of the identification. Among them, the performance of employee responsibility and successful identification is significantly positive correlation. Employee responsibility and customer responsibility performance have a significant positive effect on the benefit identification. However, environmental responsibility, employee responsibility, community responsibility and customer responsibility have a significant positive effect on the attribution identification.

\subsection{Identification process}

Some researchers study organizational identification model (Pratt, 2001), these motives drive the individual's intention and behavior; the influence of the employees on the organization, work team groups and colleagues; the identification of relationship between subordinates and superiors. Danielle Cooper \& Sherry M. B. Thatcer (2010) concerned with the influence of individual self-concept orientation and motivation on organizational identity in the process of identity motivation. The individualism orientation influence to organizational identification through self-enhancement and self-consistency; relational orientation influence to organizational identification through uncertainly reduction and depersonalized belongingness; group orientation influence to organizational identification through uncertainly reduction and depersonalized belongingness. Chen Hao (2010) analysis of employee psychological empowerment, self-efficacy, autonomy and influence will affect the organizational identification of employees. Through the regression coefficient, the influence of the work value on organizational identification is the most significant; Self efficacy, autonomy and influence on organizational identification of the influence in turn weakened. Because the work meaning reflects the process of self-realization, when employees feel that their work is valuable and meaningful, it will improve the employee's self-identity.

\section{6 comprehensive theory analysis of the mechanism of antecedent variables on organizational identification}

Some researchers study the organizational identification under the influence of internal factors, external factors and individual factors. Liu Feng Ying et al. (2010) found that, base on different tenure; there are different influence of internal factors and external factors to organizational identification. Base on the employee tenure, the organizational identification is divided into the early stage, middle stage and later stage identification. In early stage identification, external factors are the key antecedents of organizational identification; in middle stage identification, with the in-depth understanding of the organization, the organization internal factors is the main affecting factors; and in later stage identification, the external factors mainly affect organizational identification.

\section{Result and Discussion}

The research result on antecedent variables of organizational identification has become increasingly rich. Future research trends will focus on individual cognitive and psychological factors, taking the factors of the organization as the research background, combining with the common function of many factors effect to organizational identification.

Analysis on the difference of antecedents available of organization team, informal organization and organizational identification is necessary. In order to adapt to the dynamic and complex external environment, the organization continues to expand the merger or the formation of a project team led to the complexity of the structure, and there are many kinds of informal organization in the organization at the same time. Therefore, employees also have multiple identities. Previous research has indicated that employees may identify their identity in informal organization at the same time, but there is a difference in identify object and degree of identification. Therefore, subsequent research needs to matching between the antecedent variables and objects of identity and distinguish the difference of the antecedent variables of different objects of identity.

The perspective of organizational identification antecedents changed. From the research on mechanism of action of antecedents to organizational identification in recent years, the information transfer process, the mechanism of social exchange, the interpretation of the mechanism has become mature. And the operation process of enterprise development cycle, mechanism of uniformity organization, identification process, comprehensive analysis will be the trend of future research. 


\section{References}

Danielle, C., Sherry, M. B., \& Thatcher. (2010). Identification in organization: The role of self-concept orientations and identification motives. Acadamy of Management Review, 4, 516-538. http://dx.doi.org/10.5465/AMR.2010.53502693

Eisenberger, R., Huntington, R., Hutchison, S., \& Sowa, D. (1986). Perceived organizational support. Journal of Applied Psychology, 71, 500-507. http://dx.doi.org/10.1037/0021-9010.71.3.500

Fuller, J. B., Hester, K., Barnett, T., Frey, L., Reylea, C., \& Beu, D. (2006). Perceived external prestige and internal respect: New insights into the organizational identification process. Human Relations, 59, 815-846. http://dx.doi.org/10.1177/0018726706067148

Han, X. S., Jiang, Y., \& Yuan, B. (2007). Review and Prospect of research on organizational identification. Business Studies, 3, 88-97.

He, L., \& Lin, W. X. (2008). Study on the influence of different types of organizational culture on organizational identification and job involvement. Science and Technology Management Enterprise, 10, 112-120.

Lee, J., \& Peccei, R. (2007). Perceived organizational support and affective commitment: The mediating role of organization based self-esteem in the context of job insecurity. Journal of Organizational Behavior, 28, 661-685. http://dx.doi.org/10.1002/job.431

Li, Y., \& Li, W. F. (2011). High performance human resource practices contribute to organizational identification: an intermediary role model of regulation. Management World, 2, 59-67.

Liu, F. Y., \& Lu, H. Z. (2010). Research on the influence of organizational factors on the process of individual organizational identification: Base on the employee tenure. Soft Science, 9, 156-170.

Martin, R., \& Edwards, H. R. (2009). Perceived organizational support and organizational identification: an analysis after organizational formation. Human Resource Management Journal, 19, 110-118. http://dx.doi.org/10.1111/j.1748-8583.2008.00083.x

Mary, J. H., \& Majken, S. (2002). The dynamics of organizational identity. Human Relations, 8, 114-121. http://dx.doi.org/10.1177/0018726702055008181

Morgan, J. M., Reynolds, C. M., Nelson, T. J., Johanningmeier, A. R., Griffin, M., \& Andrade, P. (2004). Tales from the fieds: sources of employee identification in agribusiness. Management Communication Quarterly, 17, $360-395$. http://dx.doi.org/10.1177/0893318903258169

Thomas, J., Zagenczyk, R., Gibney, W., Timothy, F., \& Kristin L. Scott. (2011). Psychological Contracts and Organizational Identification: The Mediating Effect of Perceived Organizational Support. J Labor Res, 32, $254-281$. http://dx.doi.org/10.1007/s12122-011-9111-Z

Tyler, T. R., \& Blader, S. L. (2003). The group engagement model: procedural justice, social identity theory, and cooperative behavior. Personality and Social Psychology Review, 7, 349-361. http://dx.doi.org/10.1207/S15327957PSPR0704_07

Wang, B. Y., Li, S. L., Gao, R. G. (2011). The empirical analysis of the relationship between supervior-subordinate organizational identification and subordinate turnover intention. Contemporary Finance, 9, 221-232.

Wang, Z., \& Sun, J. M. (2011). Human resource management practices: Organizational support and employee commitment, identification -- a cross level study. Economic Management, 4, 109-116.

\section{(cc) BY}

This work is licensed under a Creative Commons Attribution 3.0 License. 